\title{
PERIGO SÍSMICO NO BRASIL E A RESPONSABILIDADE DA ENGENHARIA DE ESTRUTURAS
}

\author{
P. G. B. NÓBREGA e S. H. S. NÓBREGA \\ Universidade Federal do Rio Grande de Norte - UFRN \\ nobrega@ufrnet.br
}

Artigo submetido em junho/2016 e aceito em julho/2016

DOI: $10.15628 /$ holos.2016.4703

\section{RESUMO}

No Brasil os terremotos são relativamente raros, especialmente os de maior magnitude, sendo a probabilidade de desastres e mortes relativamente pequena a ponto de muitos projetos de engenharia não a levarem em conta, a despeito do que está estabelecido na norma brasileira de projetos de estruturas resistentes a sismo (NBR 15421). Todavia, a sismicidade do Brasil não é nula; especialmente para algumas áreas, como a borda passiva, cuja média é superior a $70 \%$ da registrada na região continental estável. Os terremotos são imprevisíveis, mas a boa engenharia não deve ser. Este artigo discute a importância da consideração das ações sísmicas nas análises das estruturas civis, fazendo uma avaliação do mapa de perigo sísmico trazido pela NBR 15421 , indicando procedimentos e condutas que devem ser tomados para o adequado projeto. Embora os projetos de algumas edificações, em algumas áreas do país, possam realmente desprezar a ação sísmica, tem-se a necessidade de discutir os procedimentos adequados para os prédios de operação especial e uso coletivo, exatamente aqueles que deveriam funcionar em caso de sinistro. Se não é possível eliminar o perigo sísmico, o objetivo é diminuir a vulnerabilidade a fim de se ter um risco sísmico aceitável, com um custo econômico e social admissíveis.

PALAVRAS-CHAVE: terremotos, perigo sísmico, risco sísmico, projetos de estruturas, NBR 15421.

\section{SEISMIC HAZARD IN BRAZIL AND THE RESPONSABILITY OF THE STRUCTURAL ENGINEERING}

\begin{abstract}
In Brazil earthquakes are rare, especially those of great magnitude, and the probability of disasters and deaths is so low that normally many engineering designs do not take them into account, regardless of what is established in the Brazilian code about the design of seismic resistant structures (NBR 15421). However, the seismicity in Brazil is not null; especially for some areas, like the passive margin, whose average is higher than $70 \%$ when compared to the stable continental region. Earthquakes are unpredictable, but the good engineering must not be. This paper makes a discussion about the importance of considering the seismic action in civil structures design.
\end{abstract}

Also, assess the seismic hazard map presented in NBR 15421 , indicating procedures and practices that should be taken to the appropriate design. Although the projects of some buildings, in some areas of the country, can really neglect the seismic action, there is the need to discuss the proper procedures for the special and operation buildings, exactly those ones who should work in case of accident. If it is impossible to eliminate the seismic hazard, the goal is to reduce the vulnerability in order to have an acceptable seismic risk, with an admissible economic and social costs.

KEYWORDS: earthquakes, seismic hazard, seismic risk, structural design, NBR 15421. 


\section{INTRODUÇÃO}

A teoria tectônica demonstra que as regiões de encontro entre placas são responsáveis pela quase totalidade da energia sísmica liberada no planeta. Um pequeno percentual restante ocorre em locais distantes destas fronteiras, nas denominadas regiões intraplaca. O território brasileiro, como um todo, situa-se em uma área intraplaca (e razoavelmente não próximo às bordas), o que se reflete, naturalmente, em uma menor atividade sísmica. Explicar a gênese da sismicidade intraplaca é um grande desafio, havendo diversos modelos propostos para explicar esta atividade conforme Assumpção et al. (2014, p.51).

As relativas baixas quantidade e magnitude destes fenômenos são responsáveis por uma "aparente sensação de segurança", o que leva os projetistas de edificações, notadamente arquitetos e engenheiros, a tradicionalmente negligenciarem as ações sísmicas na concepção, na análise e no dimensionamento das edificações civis usuais. Entretanto, para certas obras, como hidrelétricas, barragens, centrais nucleares, ou outros casos especiais, as avaliações que consideram tais eventos são normalmente realizadas, em especial por necessitarem de adaptação aos rigorosos padrões e códigos normativos internacionais.

De fato, terremotos podem provocar grandes danos, e é normalmente isso que percorre a mente quando se reflete sobre o assunto. As Figuras 1 e 2 ilustram imagens da destruição ocorrida em quatro diferentes países, conduzindo a uma conclusão. O sismo de janeiro/1995 em Kobe, no Japão, com magnitude 7,3 $\mathrm{Mw}$ ( $\mathrm{Mw}_{\mathrm{w}}$ indica a escala de magnitude de momento), resultou em cerca de 6.400 mortes, sendo uma fração significativa vitimada pelos objetos que caiam na rua (desde sinais de trânsito a fachadas de prédio e anúncios comerciais) ao colapso de edificações mais antigas, construídas antes das normas técnicas mais rigorosas. Em janeiro/2010, no Haiti, um país despreparado para este tipo de fenômeno, o abalo de magnitude 7,0 $\mathrm{M}_{\mathrm{w}}$ promoveu o caos e um número superior a 200 mil mortes. Pouco dias depois, em fevereiro/2010, verificou-se a ocorrência no Chile de um abalo muito superior, com magnitude $8,8 \mathrm{Mw}$, resultando em 795 mortes confirmadas, um número 250 vezes menor que o total do Haiti. Mais recentemente, em abril/2015 deu-se a tragédia do Nepal, um evento de magnitude 7,8 $\mathrm{Mw}$, causando mais de 8.000 mortes, 19.000 feridos e afetando a vida de 4,6 milhões de pessoas. Como o Haiti, o Nepal é um país com limitados recursos econômicos e tecnológicos.

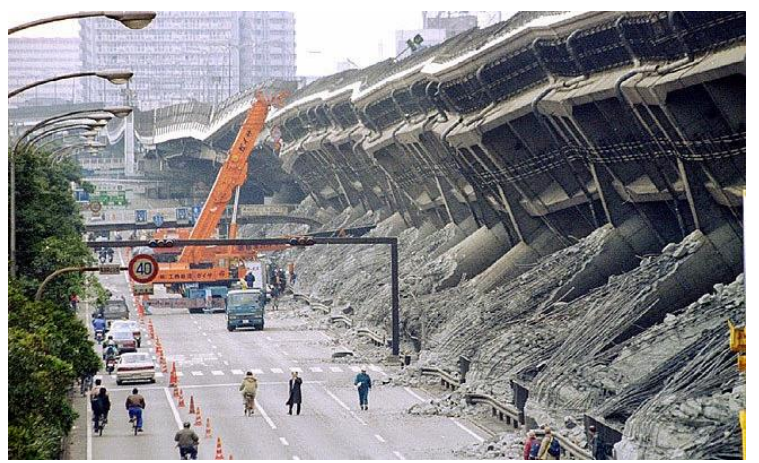

Viaduto, Kobe / Japão, 1995

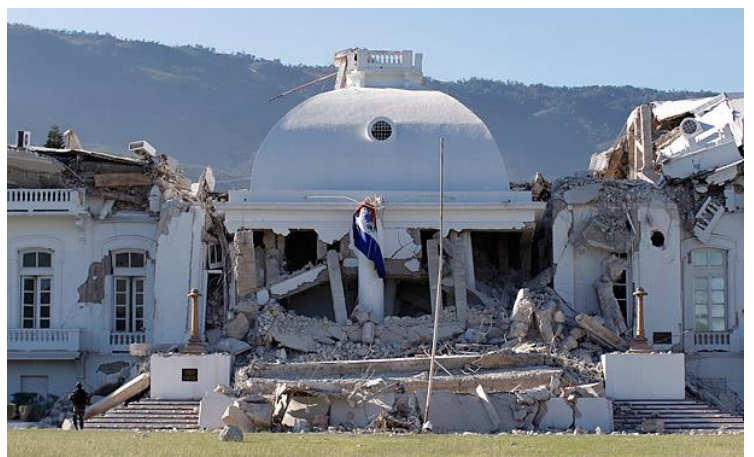

Palácio presidencial, Haiti, 2010

Figura 1: Efeitos dos sismos do Japão/1995 e Haiti/2010. 


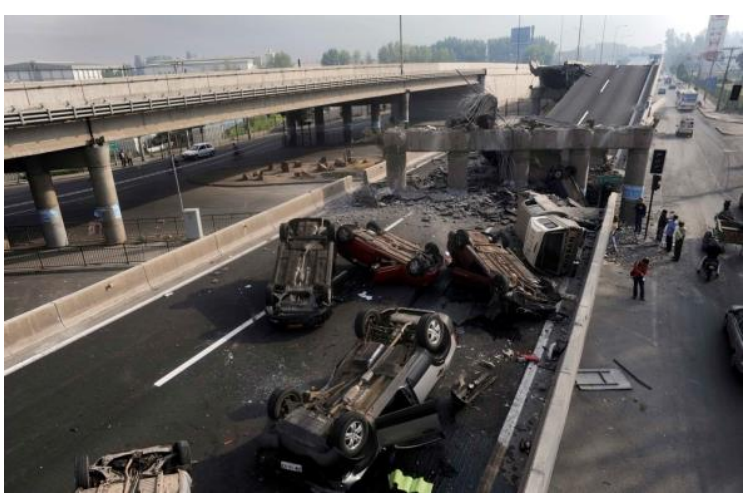

Viaduto, Santiago / Chile, 2010

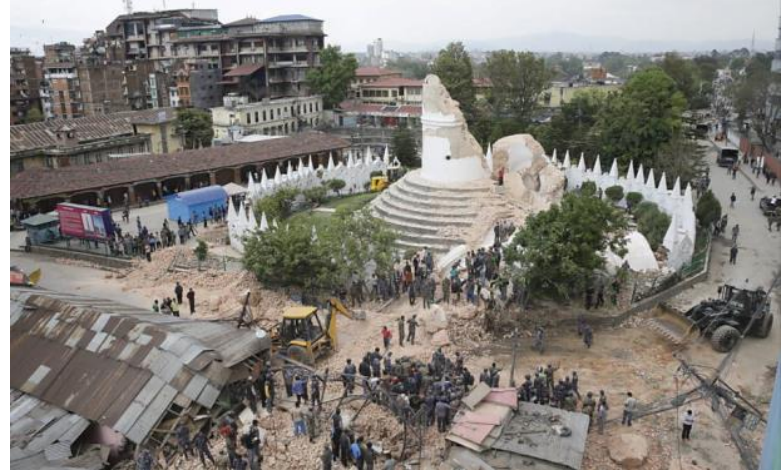

Torre Dharahara, Katmandu / Nepal, 2015

Figura 2: Efeitos dos sismos do Chile/2010 e Nepal/2015.

Destes eventos, observa-se a importância da adequada engenharia, seja no projeto ou na execução das estruturas. De todos os citados, o mais extremado foi o acontecimento chileno, inclusive um dos maiores de toda a história, justamente em relação ao qual se produziu menos mortes (embora um número não desprezível, obviamente). Mas a diferença na destruição gerada, seja material ou no tocante às vítimas, foi significativamente menor.

Pode-se considerar que o Brasil está livre da ocorrência destes fenômenos? Existem registros de tremores de magnitude suficiente para que não se negligencie estes eventos ou para que se negue a existência de algum risco? Esta segunda pergunta é mais adequada que a primeira (mais comum), mas talvez a melhor indagação seja: qual a probabilidade de termos um evento de consequências tão graves e se é viável a sua prevenção?

Coincidentemente, e felizmente, os abalos mais fortes ocorridos no Brasil aconteceram em regiões pouco habitadas, acarretando consequências mínimas para os grandes centros urbanos. Afortunadamente, conta-se apenas uma única vítima fatal de um tremor de terra no Brasil: uma criança de apenas 5 anos, lamentavelmente alcançada pelas ruínas de sua casa que veio abaixo, no povoado rural de Caraíbas, no município de Itacarambi (MG), em 9 de dezembro de 2007, em função do sismo de magnitude $4,9 \mathrm{~m}_{\mathrm{b}}$ ( $\mathrm{m}_{\mathrm{b}}$ indica a escala de magnitude com ondas de corpo $P$ ). Uma casa relativamente simples, típica das zonas rurais, certamente executada sem maiores cuidados técnicos. Saldo final de 70 casas danificadas e 6 em ruínas.

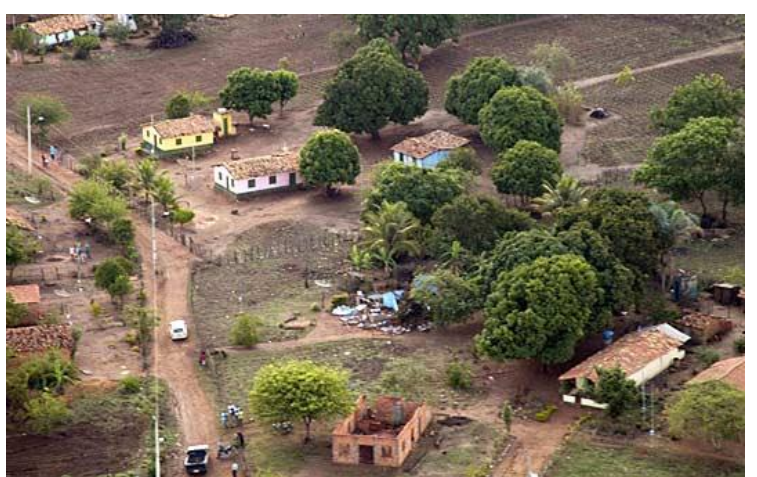

Vista aérea do povoado de Caraíbas

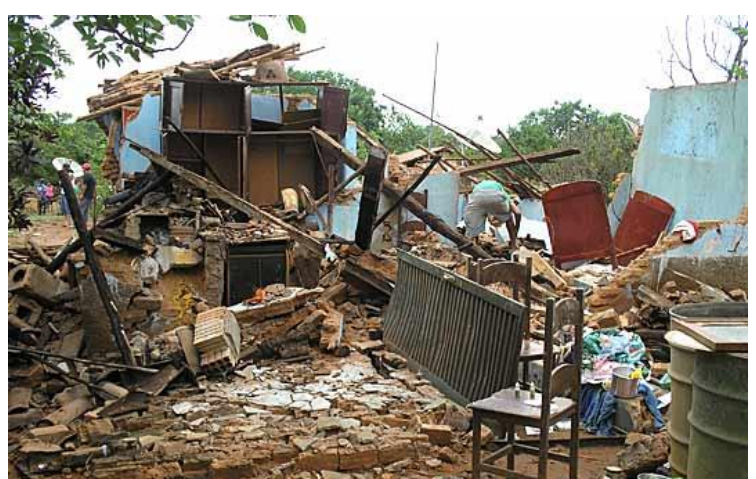

Casa destruída no povoado de Caraíbas

Figura 3: Efeitos do sismos de Itacarambi/2007.

Especificamente em relação ao Rio Grande do Norte, extensivo aos estados vizinhos do CE e $P E$, tem-se uma atípica e intensa atividade sísmica. Na região do município de João Câmara (RN), 
especialmente no período de 1986 até 1993, foram observados muitos e muitos tremores. Destacam-se, desta longa série, duas fortes ocorrências: uma de magnitude 5,1 $\mathrm{m}_{R}$ em 30/11/1986 ( $m_{R}$ indica a escala de magnitude regional, para o Brasil), e outro de magnitude 5,0 $\mathrm{m}_{R}$, em 10/03/1989; e vários outros sismos de magnitude superior a 4,0, resultando em pânico generalizado, saída da população da cidade, e muitas casas danificadas. Edificações que aparentemente não seguiam um padrão adequado de engenharia, como ainda continua a ser comum na região. A Figura 4 ilustra os danos provocados pelo sismo de 1986 em João Câmara.
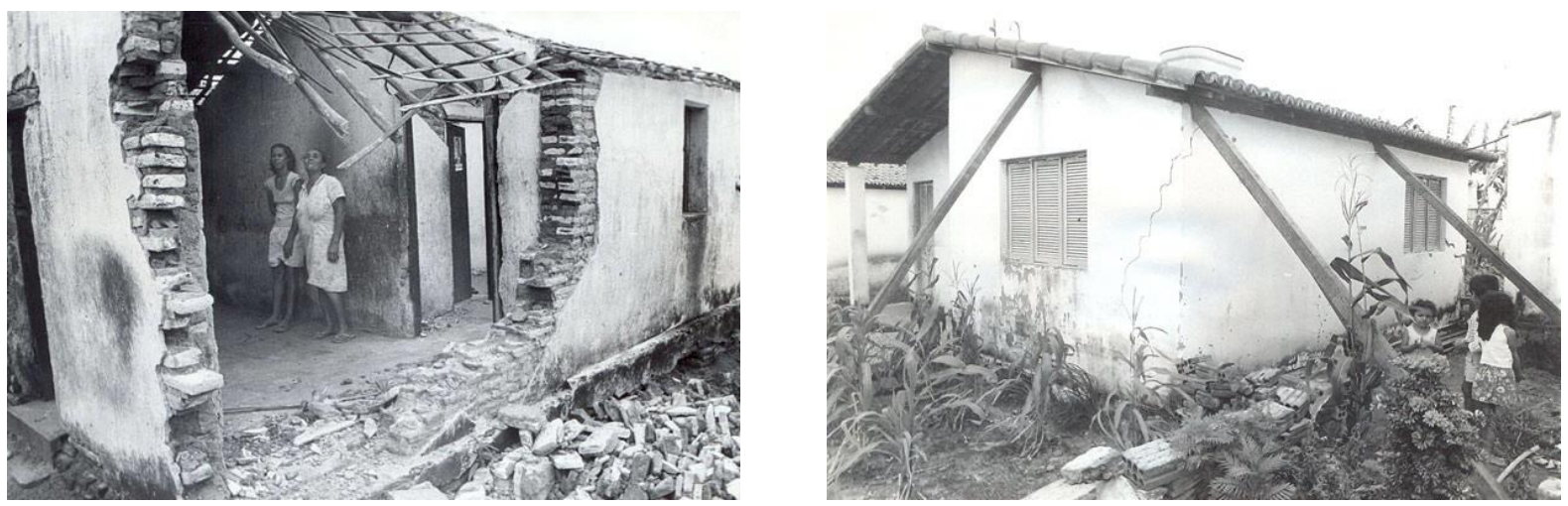

Figura 4: Edificações em João Câmara afetadas pelos sismos de 1986.

Fundamentado nesta breve introdução, indaga-se se as edificações usuais, inclusive as de pequeno e médio porte, devem realmente considerar as ações sísmicas. Seria isto um "exagero", ainda mais nos casos em que elas atenderem a um padrão adequado de engenharia? Por outro lado, tem-se que o crescimento populacional gera, inevitavelmente, adensamento dos centros urbanos, requerendo como solução para atender esta demanda a construção de edifícios de maior porte com estruturas mais altas e esbeltas, para as quais as ações dinâmicas, em geral, tornam-se relevantes, muitas vezes até determinantes do resultado do projeto. Vale a pena correr o risco em negligenciar as ações sísmicas? Contudo, é legítimo perguntar racionalmente: qual a probabilidade efetiva de um terremoto de grande porte ocorrer?

Sabe-se que existe uma norma nacional, a ABNT NBR 15421 - Projeto de Estruturas Resistentes a Sismos - Procedimento (2006), que estabelece os requisitos para os projetos estruturais, mais especificamente para as estruturas de edificações, quaisquer que sejam sua classe e destino, fazendo ela uma ressalva: "Esta Norma não se aplica a estruturas especiais, tais como pontes, viadutos, obras hidráulicas, arcos, silos, tanques, vasos, chaminés, torres, estruturas off-shore, ou em que se utilizam técnicas construtivas não convencionais, tais como formas deslizantes, balanços sucessivos, lançamentos progressivos e concreto projetado". Para essas, contudo, não há outro documento nacional balizador do projeto.

Este artigo discute a importância da consideração das ações sísmicas nas análises das estruturas civis. Faz uma descrição sucinta da sismicidade do território brasileiro e discute o mapa de perigo sísmico trazido pela NBR 15421. Apresenta, de forma didática, os principais aspectos associados aos conceitos de perigo e risco sísmico, indicando procedimentos e condutas que devem ser adotados para o adequado projeto. Destaca-se que o RN é um dos estados do Brasil onde terremotos ocorrem com maior frequência, sendo importante que o meio técnico aborde este tema com a devida consistência. 


\section{PANORAMA DA SISMICIDADE BRASILEIRA}

Efetivamente, ao se comparar o Brasil a outras regiões do planeta, ou mesmo à América do Sul, pode-se constatar que a sua atividade sísmica é menor. E relativamente baixa.

Poucos terremotos "genuinamente" brasileiros ultrapassaram a magnitude 6,0. Destacamse: o famoso acontecimento da Serra do Tombador (MT) no ano de 1955, com magnitude 6,2 $\mathrm{m}_{\mathrm{b}}$; o sentido no estado do ES, também em 1955, com magnitude 6,1 mb e epicentro no Oceano, a cerca de $300 \mathrm{~km}$ da costa; e o mais recente, em 2003, de magnitude 7,1 mb, em plena Floresta Amazônica, mas em função da grande profundidade do hipocentro, não foi sentido de forma significativa nas (poucas) cidades mais próximas.

Assumpção et al (2014) apresentam um mapa de sismicidade a partir dos dados constantes do catálogo brasileiro com magnitudes acima de 3,0 (um total aproximado de 800 eventos), Figura 5(a). Os mesmos autores realizaram uma revisão nos registros dos diversos eventos, fundamentados na confiabilidade proporcionada pela disponibilidade dos equipamentos ao longo dos anos, especialmente naqueles relatados apenas em jornais e livros, a fim de obterem um mapa de epicentros mais coerente e confiável. Este segundo resultado é indicado na Figura 5(b). As imagens mostram claramente a existência de áreas ativas e de grandes regiões quase completamente assísmicas. As siglas GS, CBS, Pb, e outras, denominam as regiões geográficas (por exemplo, GS é "Guyana shield”, CBS é "Central Brazil shield” e Pb é Parnaíba).

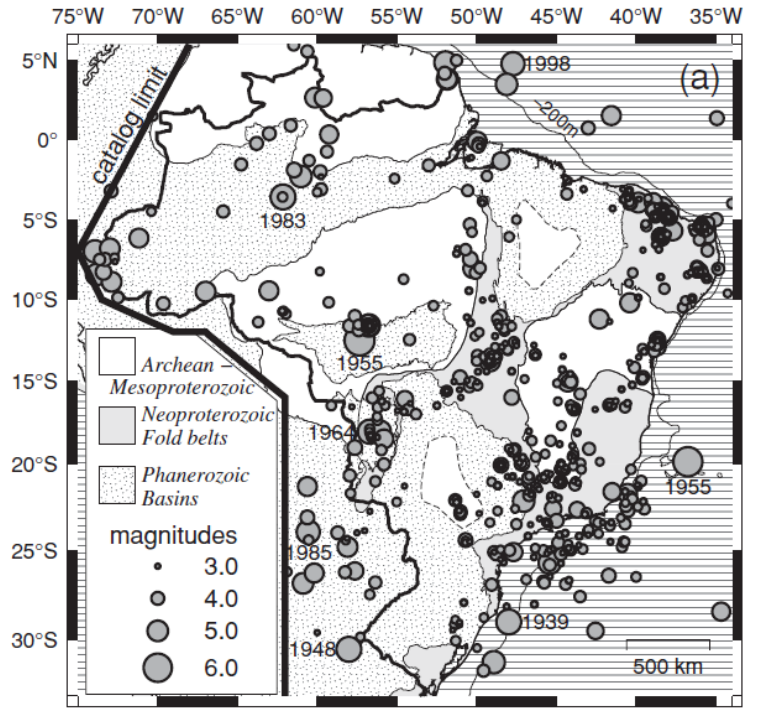

(a)

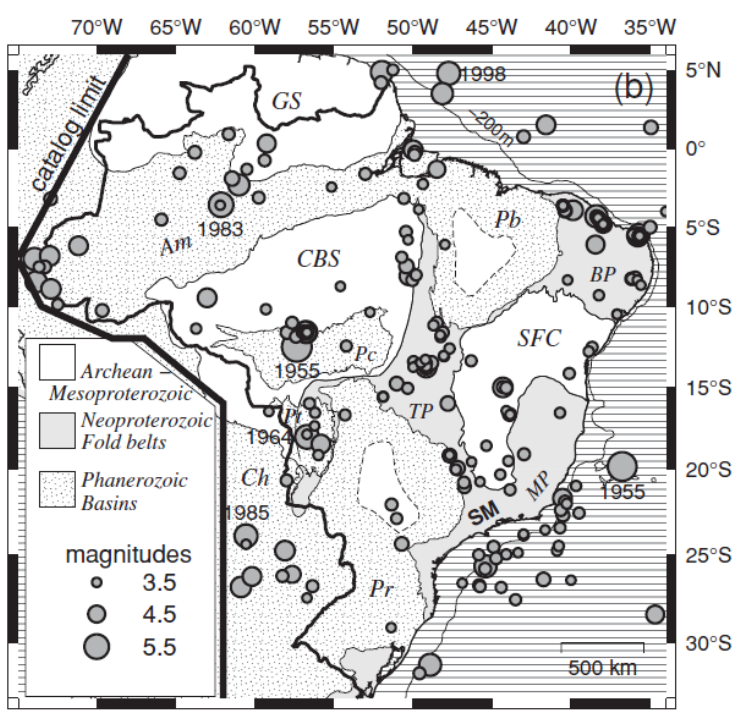

(b)

Figura 5: Mapas de sismicidade do Brasil.

Fonte: Assumpção (2014).

É verdade que abalos de magnitude superior a 7,0 $\mathrm{mb}_{\mathrm{b}}$ (chegando inclusive a 7,5 $\mathrm{mb}_{\mathrm{b}}$ ) já foram registrados em cidades brasileiras. Muito recentemente, em novembro/2015, isto ocorreu mais de uma vez nas cidades acreanas, especialmente em Feijó (AC); mas os epicentros dos tremores foram localizados no Distrito de Iberia, no Peru, a 221 km de Feijó, em uma região próxima à fronteira. Diversos outros sismos de magnitude superior a 5,0, ou mesmo 6,0, foram sentidos ao longo dos anos, em diversas cidades do país, com epicentros identificados no Chile, na Argentina, no Peru, na Bolívia, ou mesmo no Oceano Atlântico. 
Também é verdade que algumas regiões do Brasil registram mais abalos, como os estados de MG, MT, RN, CE e o centro de GO, concentrando estatisticamente as ocorrências, mas em geral, os sismos nesses locais não costumam ultrapassar a magnitude 4,0. Dois "enxames" sísmicos merecem citação, ambos ocorridos no RN: o de 1986 (na região da cidade de João Câmara) e o de 2013 (na região da cidade de Pedra Preta). O estado do AC, por sua vez, registra as maiores magnitudes, mas isto se deve à particularidade da proximidade de sua fronteira com os países andinos, de muita atividade sísmica.

O "Global Seismic Hazard Assessment Program (GSHAP)" foi um projeto que envolveu várias instituições internacionais, iniciado em 1992 e concluído em 1999, tendo por objetivo primário construir um mapa global de perigo sísmico de forma coordenada, baseado em métodos probabilísticos de avaliação. A Figura 6 ilustra.

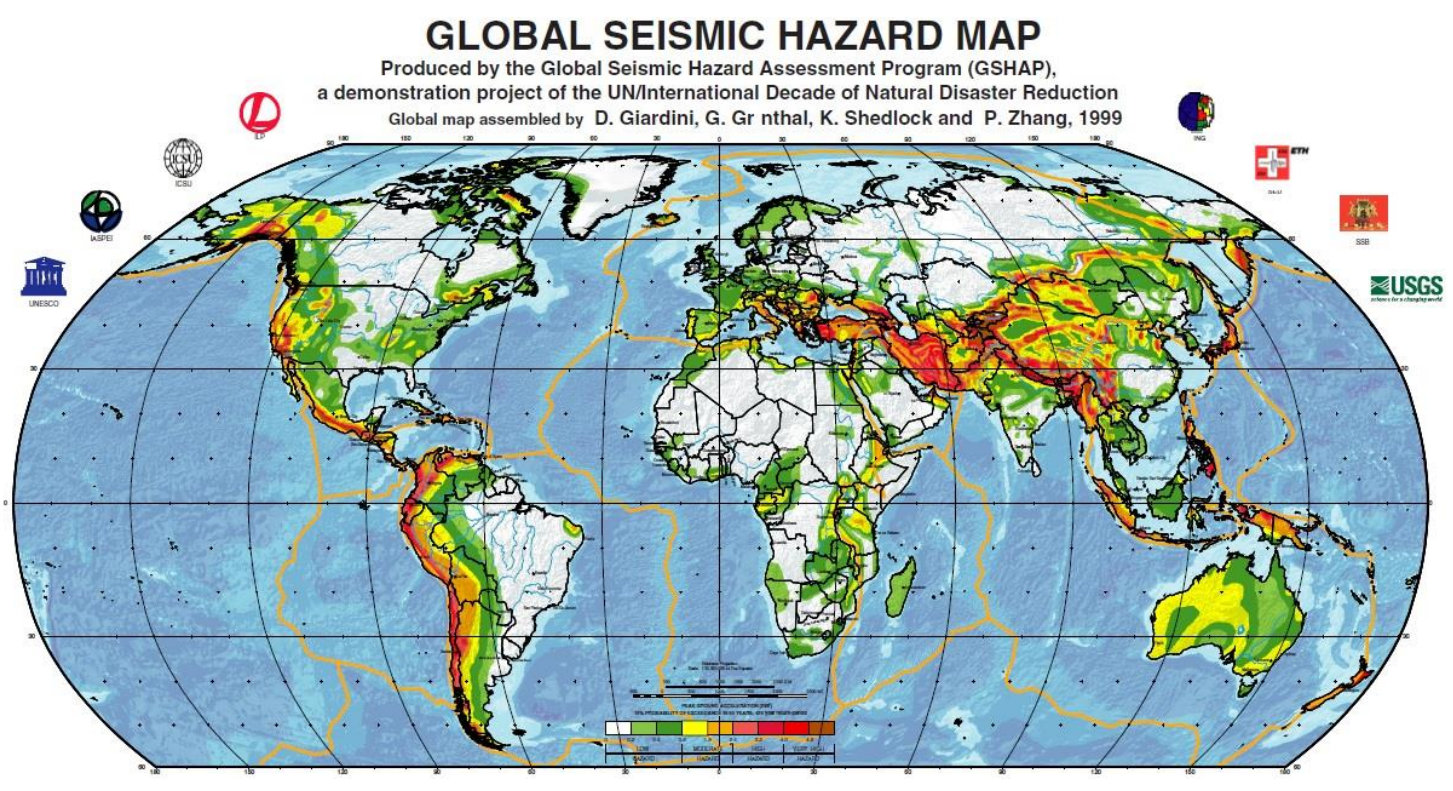

Figura 6: Mapa do perigo sísmico global.

Fonte: adaptado de GSHAP (1999).

O mapa mostra o Brasil com um perigo relativamente muito baixo, com acelerações horizontais características normalmente inferiores a $0,4 \mathrm{~m} / \mathrm{s}^{2}$. Exceções são uma porção do Nordeste, reunindo frações dos estados do RN, PB e CE, e a parte oeste das Regiões Norte e CentroOeste, devido à sua proximidade com a Cordilheira dos Andes. A Figura 7 ilustra.
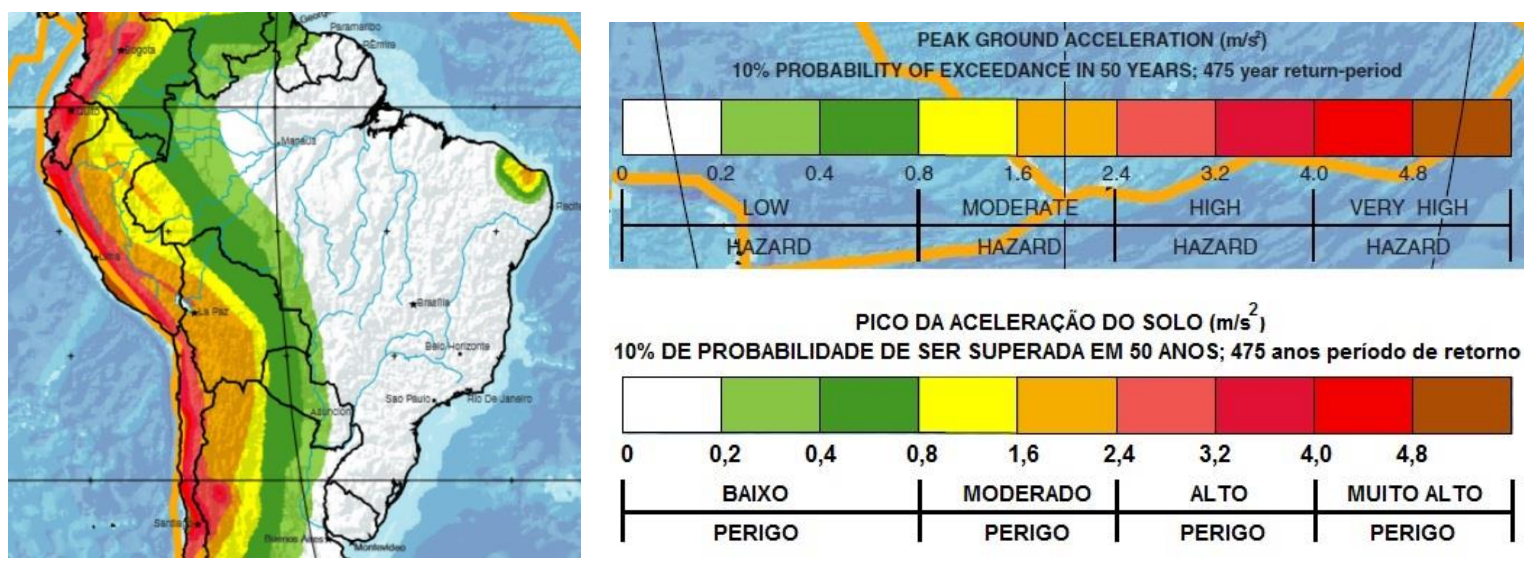

PICO DA ACELERACÃO DO SOLO $\left(\mathrm{m} / \mathrm{s}^{2}\right)$ $10 \%$ DE PROBABILIDADE DE SER SUPERADA EM 50 ANOS; 475 anos periodo de retorno

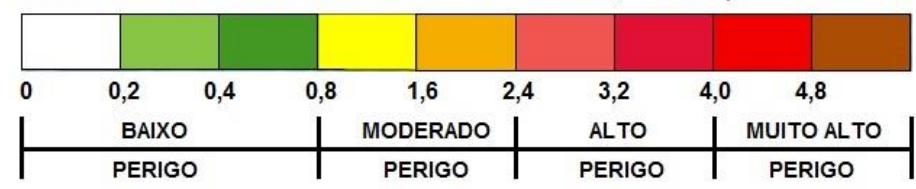

Figura 7: Fração do mapa do perigo sísmico global, destacando-se o Brasil.

Fonte: adaptado de GSHAP (1999). 
Lopes e Nunes (2011) afirmam de maneira concisa e precisa: "O nível de atividade sísmica no Brasil é classificado como baixo, com ocorrência média de menos de dois sismos com magnitudes maiores que $4 \mathrm{~m}_{\mathrm{b}}$ por ano, um sismo com magnitude maior que $5 \mathrm{~m}_{\mathrm{b}}$ a cada seis anos, e um sismo de magnitude $6 \mathrm{~m}_{\mathrm{b}}$ a cada 45 anos. Mesmo com frequência muito baixa, não é impossível a ocorrência de sismos com magnitudes de até $7,5 \mathrm{mb}_{\mathrm{b}}$, sendo que, nesse caso, o período de recorrência desse tipo de evento no Brasil é em torno de 885 anos".

Para efeito de comparação, perceba-se que na região andina os sismos de magnitude superior a 5 ocorrem em média duas vezes por semana, e os de magnitude superior a 6 acontecem uma vez por mês. Frise-se: o risco sísmico no Brasil é baixo, mas não é nulo. Assumpção et al (2014) destacam que a borda brasileira passiva, por exemplo, apresenta $70 \%$ mais terremotos (com magnitude acima de 3,5 ) que a média da região continental estável.

\section{ZONEAMENTO SÍSMICO BRASILEIRO}

O território brasileiro é dividido, segundo a NBR 15421 baseada no mapa do GSHAP, em cinco zonas sísmicas, conforme ilustra a Figura 8. Verifica-se que parte amplamente majoritária do território encontra-se situada na Zona 0 , para a qual considera-se muito baixo o perigo sísmico, embora, historicamente, alguns dos eventos mais intensos tenham ocorrido nesta área, além dela ser o local onde se concentram os maiores centros urbanos e a maior quantidade de grandes estruturas como hidrelétricas, barragens, pontes, torres e edifícios altos.

Vasconcelos (2010) alerta que o mapa de zonas sísmicas da NBR 15421 não incorpora as características da sismicidade brasileira, por haver usado os dados de um mapa de perigo sísmico em escala mundial, mostrando uma regionalização bastante simplificada.

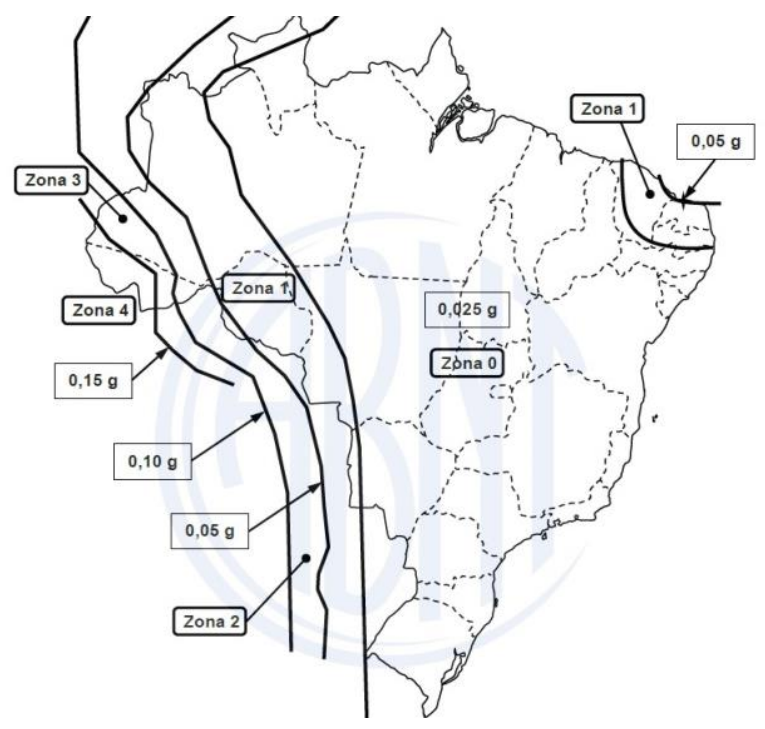

Figura 8: Mapa de zonas sísmicas do Brasil e acelerações correspondentes. Fonte: NBR 15421 (2006).

A Tabela 1 ilustra a associação das zonas sísmicas às acelerações indicadas na NBR 15421. Os valores atribuídos situam-se entre 2,5\% e 15\% de " $\mathrm{g}$ " (aceleração da gravidade), e estes valores referem-se a terrenos de rocha, onde não há amplificação sísmica pelo solo (para outros terrenos, outros tipos de solo, haverá tal amplificação). Para melhor exemplificação, tem-se, de forma geral, que dois prédios iguais podem sofrer muito ou pouco dano, dependendo apenas do tipo de solo 
onde estão. Solos mais rígidos (rochas por exemplo) vibram menos; solos menos rígidos amplificam as ondas sísmicas, causando maior movimentação à estrutura.

A norma define ainda as denominadas "Categorias Sísmicas" para as estruturas, função da zona sísmica em que ela foi construída, que estão relacionadas, por sua vez, aos métodos e requisitos de análise estrutural preconizados pela NBR 15421. Observa-se que o grau de complexidade requerido aumenta com a intensidade das acelerações. Estas indicações também são feitas na Tabela 1. Admita-se, para esta tabela, as siglas: MFHE = método das forças horizontais equivalentes; $\mathrm{ME}$ = método espectral; e MHAT = método do histórico de acelerações no tempo.

Tabela 1: Zonas sísmicas e variáveis associadas.

\begin{tabular}{c|c|c|c}
\hline $\begin{array}{c}\text { Zonas } \\
\text { Sísmica }\end{array}$ & Aceleração & Categoria & Métodos aplicáveis para a análise estrutural \\
\hline 0 & $\mathrm{a}_{\mathrm{g}}=2,5 \% \mathrm{~g}$ & $\mathrm{~A}$ & Nenhum requisito de resistência sísmica é exigido \\
1 & $2,5 \% \mathrm{~g} \leq \mathrm{a}_{\mathrm{g}} \leq 5 \% \mathrm{~g}$ & $\mathrm{~A}$ & Procedim. simplificado da força sísmica horizontal \\
2 & $5 \% \mathrm{~g} \leq \mathrm{a}_{\mathrm{g}} \leq 10 \% \mathrm{~g}$ & $\mathrm{~B}$ & MFHE ou ME ou MHAT \\
3 & $10 \% \mathrm{~g} \leq \mathrm{a}_{\mathrm{g}} \leq 15 \% \mathrm{~g}$ & $\mathrm{C}$ & MFHE ou ME ou MHAT \\
4 & $\mathrm{ag}_{\mathrm{g}}=15 \% \mathrm{~g}$ & $\mathrm{C}$ & MFHE ou ME ou MHAT \\
\hline
\end{tabular}

Evidencia-se, pela Figura 8, que a quase totalidade do território nacional está inserido na zona 0. Para esta zona, embora exista a indicação da aceleração correspondente $(2,5 \% \mathrm{~g})$, há a indicação expressa na NBR 15421: "Para as estruturas localizadas na zona sísmica 0, nenhum requisito de resistência sísmica é exigido." Ou seja, apenas o projeto estrutural convencional é suficiente, não sendo necessário qualquer procedimento especial.

Para a zona 1, existe a seguinte previsão: "As estruturas localizadas na zona sísmica 1 devem apresentar sistemas estruturais resistentes a forças sísmicas horizontais em duas direções ortogonais, inclusive com um mecanismo de resistência a esforços de torção". Além disso, as estruturas devem resistir a forças horizontais aplicadas no piso, que simulam as ações sísmicas. Aqui pode ser usado o procedimento simplificado da força sísmica horizontal.

Nas demais zonas (2, 3 e 4) devem ser utilizados procedimentos específicos de análises sísmicas: o método das forças horizontais equivalentes (método estático) ou outros mais complexos como o método espectral ou o da história das acelerações no tempo (métodos dinâmicos), a critério do projetista.

A apresentação detalhada destes métodos, além de aplicações numéricas para edificações com diferentes alturas, podem ser encontrados em Dantas, Nóbrega e Nóbrega (2014a) ou em Paiva Neto, Nóbrega e Nóbrega (2016).

\section{RISCO DE ENGENHARIA E RISCO SÍSMICO}

A sensação de "risco" para cada indivíduo é algo de extrema subjetividade e está associada a uma ideia da probabilidade dele se encontrar no local do sinistro ("aqui não acontece e não há de acontecer...", "não ocorrerá comigo...").

Esta percepção está relacionada com o tipo de sociedade, estilo de vida, satisfação de suas necessidades, e a informação disponível e circulante em seu meio. Depende, inclusive, de sua personalidade, experiência individual e no grupo, e a disposição interior para se expor ao perigo. 
Tem-se, ademais, que a negação e o desconhecimento frente a um perigo real aumentam a vulnerabilidade individual e social.

De forma geral, as probabilidades de alguém morrer em acidentes naturais são relativamente pequenas. Alguns exemplos numéricos da chance de se incorrer em mortes (amplamente disponíveis na literatura e em sites da internet, embora dependam do país em questão e mudem a cada ano) são: (i) por câncer = 1:7; (ii) por acidente de carro = 1: 120; (iii) por acidente de avião = $1: 10.000$; (iv) por enchente = $1: 30.000$; (v) por curto circuito =1:84.000; (vi) por picada de abelha ou vespa $=1: 60.000$; (vii) por terremoto $=1: 130.000$.

Borden e Cutter (2008) examinaram os padrões de mortalidade devido a perigos naturais nos EUA entre os anos 1970 e 2004, apresentando o gráfico indicado na Figura 9. As mortes causadas por terremoto estão juntas com aquelas devidas a vulcões e tsunamis, sob o grupo "Geofísica", correspondendo a uma fração irrisória do todo.

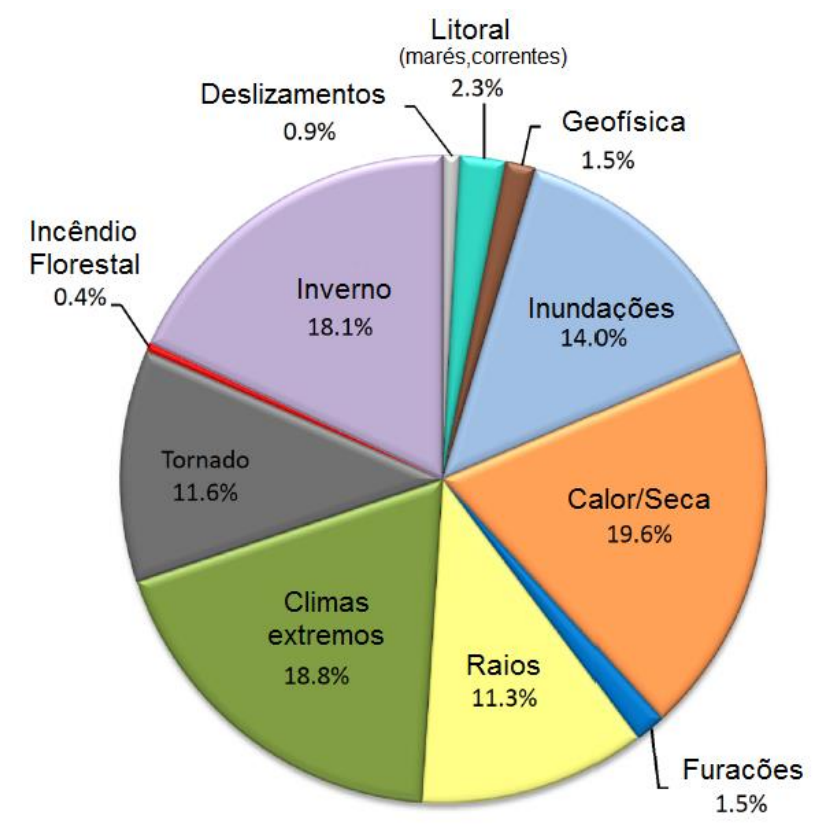

Figura 9: Mapa de mortalidade em desastres naturais em função do tipo de evento. Fonte: adaptado de Borden e Cutter (2008).

Do ponto de vista da Engenharia, todavia, o risco de um desastre não está relacionado apenas com a probabilidade do mesmo ocorrer, mas igualmente com as expectativas de perdas que ele provocaria. Na teoria da decisão, tem-se:

$$
R=P \times L
$$

sendo $\mathrm{R}=$ risco; $\mathrm{P}$ = probabilidade de um desastre ocorrer; $\mathrm{e} \mathrm{L}$ = valor econômico ao qual o desastre implica.

Assim, o risco de um evento que possa ter alta probabilidade de ocorrência, mas que induz a poucas perdas, assemelha-se ao risco de outro desastre, de probabilidade muito pequena, mas de consequências de grande monta. Nos dois casos o risco é o mesmo, exigindo condutas similares de prevenção.

Na Sismologia, os conceitos de perigo e risco (sísmicos, no caso) são similares aos da Engenharia, mas possuem certas peculiaridades. Constantemente o engenheiro e o sismologista não falam o mesmo "idioma". 
O perigo sísmico é um fenômeno que tem potencial para causar dano. A avaliação do perigo sísmico define, para uma certa região, um evento sísmico esperado que pode resultar em destruição e vítimas, podendo ser conduzido por duas abordagens distintas: a determinística e a probabilística. A primeira abordagem resulta em um sismo específico, particular, que produzirá os níveis máximos de movimento naquela região. Os dados de saída (a aceleração, a velocidade ou o deslocamento do solo de pico, e o espectro de resposta) podem ser usados diretamente nas aplicações de engenharia. Na abordagem probabilística, o perigo é estimado em termos de um parâmetro de movimento do solo e sua probabilidade de ser excedido (ou período de retorno). Os dados de saída agora são mapas de probabilidade sísmica da região, contendo os valores máximos do parâmetro escolhido e o período de retorno. Vide, por exemplo, esta indicação no quadro da Figura 7 (mapa da GSHAP).

O Risco sísmico é o dano que alguém ou algo, vulnerável, está submetido quando exposto ao perigo, representando uma medida das perdas esperadas (econômicas, humanas e sociais), como resultado de sismos futuros, e a probabilidade das mesmas ocorrerem para um certo período de tempo de exposição.

O estudo do perigo sísmico é um passo inicial, e fundamental, para o posterior estudo do risco sísmico. Tem-se que o perigo é caracterizado por 3 parâmetros: o nível de perigo (a severidade), a sua frequência, e a localização. Já o risco é definido por 4 parâmetros: a probabilidade, o nível de severidade, o período de tempo e a localização. Dá-se um exemplo simples e hipotético, cotidiano, para ajudar a compreender estes conceitos: a cada mês acontece um acidente com vítima fatal no cruzamento da rua " $A$ " com a rua " $B$ "; este é o perigo. O risco significa que existe uma probabilidade de $\mathrm{X} \%$ da pessoa vir a sofrer um acidente fatal no cruzamento da rua " $A$ " com a rua " $B$ ", se ela utilizar esta avenida uma vez por dia, no período de 15 anos.

O risco sísmico pode ser expresso ainda como:

Risco Sísmico $=$ Perigo Sísmico $\times$ Vulnerabilidade Sísmica

Ou seja, se não é possível alterar o perigo, pois ele depende essencialmente das características sísmicas da região e do tempo de exposição, resta interferir na vulnerabilidade para amenizar o risco.

Esta é a filosofia da conhecida frase "Earthquakes don't kill people, buildings do" (em tradução livre: terremotos não matam pessoas, as edificações sim). Neste caso, deve-se ter uma postura seja em relação às novas construções, que sigam os preceitos estabelecidos em norma, ou seja em relação às construções antigas, anteriores à regulamentação sísmica.

Para as edificações novas, Dantas; Nóbrega e Nóbrega (2014b) expõem alguns dos princípios básicos que devem nortear a concepção estrutural em regiões de atividade sísmica. Para as edificações antigas, Stolovas (2009), por exemplo, detalha uma metodologia de avaliação da vulnerabilidade que poderia ser utilizada no Brasil com relativa facilidade e já considerando a devida adaptação.

Voltando ao exemplo simplório do acidente de trânsito, diminuir-se-ia a vulnerabilidade utilizando um veículo que possuisse air bags, sistema de freios $A B S$, dirigindo-se neste cruzamento com cuidado redobrado e com velocidade reduzida, dentre outros aspectos. Caso se utilizasse outra rua, estar-se-ia eliminando o perigo. 
Concluindo, o Estado, por meio de suas instituições e leis, deve avaliar com responsabilidade e critério científico este risco, quantificando a vulnerabilidade da sociedade a cada desastre natural. $O$ grau de vulnerabilidade descreve exatamente se um sistema é suscetível ou resiliente à ocorrência dos terremotos. É justamente responsabilidade das autoridades evitar, ou reduzir, o risco.

Naturalmente, construções mais resilientes são muito mais caras, e países com menos recursos financeiros, como o Brasil, nem sempre podem fazer a preparação ideal. Mas, nesta consideração pode-se diferenciar o que é uma edificação privada, de uso privado, de uma edificação privada, de uso coletivo, ou uma edificação de uso público e essencial, como hospitais, escolas, quartéis de polícia e do corpo de bombeiros, sedes de governo, centrais de comunicação, de segurança e de operações em emergência, estações de tratamento de água e esgoto, dentre outras, as quais necessitam sempre ser objeto de atenção especial.

\section{INTERPRETAÇÃO DAS ACELERAÇÕES DAS ZONAS SÍSMICAS}

Perceba-se que o aspecto físico mais "palpável” do mapa de zonas sísmicas (Figura 8) é a aceleração, dada, inclusive, em fração da aceleração da gravidade. O que ela significa, em termos reais? O valor $10 \% \mathrm{~g}$, por exemplo, é relativamente alto ou baixo?

É inadequado relacionar diretamente a aceleração com a magnitude do sismo, pois esta é uma grandeza que essencialmente relaciona um sismo com o outro, ou com a energia que é liberada pelo mesmo, mas que independe da forma como ele é sentido pelas pessoas. A magnitude pode ser avaliada por diversas escalas de medição, como a de Richter, a mais famosa delas, uma escala logarítmica desenvolvida em 1935, sem unidade e sem limites de valores, que faz a estimativa a partir dos registros gráficos obtidos pelos sismógrafos. Após a escala Richter diversas outras surgiram, cada uma com as suas características próprias, criadas para diversas finalidades, sejam elas o cálculo da magnitude para uma determinada região ou país, para certo intervalo de profundidade, entre outros aspectos.

Todas estas escala, todavia, não servem para avaliar objetivamente as consequências do sismo em um determinado local, especialmente em zonas urbanas, pois isso depende fundamentalmente, além da magnitude, da profundidade do hipocentro, da distância entre o epicentro e a área considerada, da constituição geológica da região, da qualidade das construções, dentre outros aspectos.

O parâmetro que melhor representa os efeitos e danos produzidos pelos terremotos é a intensidade, e não a magnitude. A escala de intensidade Mercalli Modificada é a mais conhecida, porém é qualitativa e subjetiva. Ou seja, dois diferentes sismos com diferentes magnitudes podem provocar a mesma intensidade, ou um sismo de magnitude maior poder ser classificado com intensidade inferior ao outro, apenas porque está em uma profundidade focal e/ou distância epicentral superior ao segundo.

De qualquer forma, existe, evidentemente, certa correlação entre magnitude e intensidade, o que serve mais para estabelecer uma referência, especialmente em relação a eventos antigos, quando não registrados pelos equipamentos. 
Tabela 2: Escala de intensidade Mercalli Modificada (NUNES, LOPES 2010).

\begin{tabular}{|c|c|c|}
\hline $\begin{array}{l}\text { Intensidade } \\
\text { Mercalli Modif. }\end{array}$ & Descrição do nível de intensidade & $\begin{array}{l}\text { Aceleração } \\
(\% g)\end{array}$ \\
\hline $\begin{array}{c}\text { I } \\
\text { (imperceptível) }\end{array}$ & $\begin{array}{l}\text { Não sentido, exceto em condições extremamente favoráveis. Leves efeitos de } \\
\text { período longo de terremotos grandes e distantes. Registrado ("sentido") apenas } \\
\text { pelos sismógrafos. }\end{array}$ & - \\
\hline $\begin{array}{c}\text { II } \\
\text { (muito fraco) }\end{array}$ & $\begin{array}{l}\text { Sentido apenas por algumas pessoas, especialmente em prédios altos. Objetos } \\
\text { leves podem balançar. }\end{array}$ & $<0,3$ \\
\hline $\begin{array}{c}\text { III } \\
\text { (fraco) }\end{array}$ & $\begin{array}{l}\text { Sentido por algumas pessoas em casa, especialmente em prédios altos. Alguns } \\
\text { objetos pendurados oscilam. Vibração parecida com a da passagem de um } \\
\text { caminhão leve. Duração estimada. Pode não ser reconhecido como um abalo } \\
\text { sísmico. }\end{array}$ & $0,4-0,8$ \\
\hline $\begin{array}{c}\text { IV } \\
\text { (moderado) }\end{array}$ & $\begin{array}{l}\text { Sentido em casa por muitas pessoas, e na rua por poucas pessoas durante o dia. À } \\
\text { noite algumas pessoas despertam. Pratos, janelas e portas vibram, e as paredes } \\
\text { podem ranger. Os carros e motos parados balançam visivelmente. A vibração é } \\
\text { semelhante à provocada pela passagem de veículos pesados ou à sensação de uma } \\
\text { pancada de uma bola pesada nas paredes. }\end{array}$ & $0,8-1,5$ \\
\hline $\begin{array}{c}\mathrm{V} \\
\text { (forte) }\end{array}$ & $\begin{array}{l}\text { Sentido por praticamente todas as pessoas; muitos despertam. As pessoas } \\
\text { conseguem identificar a direção do movimento. Líquido em recipiente é } \\
\text { perturbado. Objetos pequenos e instáveis são deslocados. Portas oscilam, fecham, } \\
\text { abrem. Os movimentos de pêndulos podem parar. }\end{array}$ & $1,5-4$ \\
\hline $\begin{array}{c}\mathrm{VI} \\
\text { (forte) }\end{array}$ & $\begin{array}{l}\text { Sentido por todas as pessoas; muitos se amedrontam e saem às ruas. Pessoas } \\
\text { andam sem firmeza. Algumas mobílias pesadas podem se movimentar. Louças e } \\
\text { alguns vidros de janelas são quebrados. Objetos e livros caem de prateleiras. } \\
\text { Observação de danos moderados em estruturas civis de má qualidade. Pequenos } \\
\text { sinos tocam em igrejas e escolas. }\end{array}$ & $4-8$ \\
\hline $\begin{array}{l}\text { VII } \\
\text { (muito forte) }\end{array}$ & $\begin{array}{l}\text { Efeitos sentidos por pessoas que estão dirigindo automóveis. Difícil manter-se de } \\
\text { pé. Móveis são quebrados. Danos pequenos em edifícios bem construídos, danos } \\
\text { moderados em casas bem construídas, e danos consideráveis em estruturas mal } \\
\text { construídas. Algumas chaminés sofrem colapso. Queda de reboco, ladrilhos e } \\
\text { tijolos mal assentados. Ondas em piscinas. Pequenos escorregamentos de } \\
\text { barrancos arenosos. As águas dos açudes ficam turvas com a movimentação do } \\
\text { lodo. Grandes sinos tocam. }\end{array}$ & $8-15$ \\
\hline $\begin{array}{l}\text { VIII } \\
\text { (muito forte) }\end{array}$ & $\begin{array}{l}\text { Danos em construções normais, com colapso parcial. Algum dano em construções } \\
\text { reforçadas. Queda de estuque e alguns muros de alvenaria. Queda de chaminés, } \\
\text { monumentos, torres e caixas d'água. Galhos quebram-se das árvores. Trincas no } \\
\text { chão. Afeta a condução dos automóveis. A mobília pesada sofre movimentações e } \\
\text { pode virar. Mudanças nos fluxos ou nas temperaturas das fontes e poços. }\end{array}$ & $15-30$ \\
\hline $\begin{array}{c}\text { IX } \\
\text { (muito forte) }\end{array}$ & $\begin{array}{l}\text { Pânico generalizado. Construções comuns bastante danificadas, às vezes colapso } \\
\text { total. Danos em construções reforçadas e em grandes edifícios, com colapso } \\
\text { parcial. Alguns edifícios são deslocados para fora de suas fundações. Tubulação } \\
\text { subterrânea quebrada. Rachaduras visíveis no solo. }\end{array}$ & $30-60$ \\
\hline $\begin{array}{c}\mathrm{X} \\
\text { (catastrófico) }\end{array}$ & $\begin{array}{l}\text { Maioria das construções destruídas até nas fundações. Danos sérios a barragens e } \\
\text { diques. Grandes escorregamentos de terra. Água jogada nas margens de rios e } \\
\text { canais. Trilhos levemente entortados. }\end{array}$ & $60-100$ \\
\hline $\begin{array}{c}\mathrm{XI} \\
\text { (catastrófico) }\end{array}$ & $\begin{array}{l}\text { Poucas estruturas de alvenaria não colapsam totalmente. Pontes são destruídas e } \\
\text { os trilhos dos trens são completamente entortados. As tubulações subterrâneas } \\
\text { são completamente destruídas. }\end{array}$ & $100-200$ \\
\hline $\begin{array}{c}\text { XII } \\
\text { (catastrófico) }\end{array}$ & $\begin{array}{l}\text { Destruição quase total. A paisagem é modificada com a topografia sendo } \\
\text { distorcida. Grandes blocos de rocha são deslocados. Objetos são jogados ao ar. } \\
\text { Essa intensidade nunca foi observada no período histórico. }\end{array}$ & $>200$ \\
\hline
\end{tabular}

Em relação às acelerações, que são a variável fundamental do mapa de zoneamento sísmico da NBR 5421, vale a pena tomar emprestada a interessante adaptação da escala de intensidade Mercalli Modificada, realizada por Lopes e Nunes (2011), que traz uma série de apontamentos 
práticos para cada grau de intensidade desta escala, além de estabelecer uma relação com a aceleração da gravidade. Pode-se, agora, ter uma ideia mais razoável do requerido pela norma. Perceba-se que cada grau nesta escala corresponde a cerca de o dobro da aceleração do grau anterior.

É imperativo reafirmar que são aplicadas muitas outras ponderações para a análise estrutural da edificação, além deste valor de aceleração, considerando-se desde o tipo de solo até as características materiais, geométricas e aspectos de sua concepção.

Percebe-se, em linhas gerais, que a aceleração da zona 0 , em relação a qual nenhum requisito de resistência sísmica é exigido, está associada ao grau $V$ da escala Mercalli Modificada. $\mathrm{Na}$ descrição deste nível tem-se que o sismo é sentido por praticamente todos, que despertam aqueles que estavam dormindo, e que objetos pequenos são deslocados. Não há alusão a danos em edificações. Tem-se, em linhas gerais, que o intervalo de intensidade de I a $V$, desta escala, é pouco relevante em termos de risco sísmico.

A zona 1, por sua vez, e o estado do RN em particular, com aceleração entre $2,5 \% \mathrm{~g}$ e $5 \% \mathrm{~g}$, estaria associado aos graus V e VI. Para a intensidade VI há a indicação que o sismo é sentido por todos, inclusive havendo certo pânico, com louças e vidros de janelas quebradas, e o aparecimento de danos menores em edificações de má qualidade.

Às zonas 2 e 3 são atribuídas acelerações entre $5 \% g$ e $10 \% g$, e $10 \% g$ e $15 \% g$, respectivamente, associadas às intensidades VI e VII da escala Mercalli Modificada. Para a intensidade VII tem-se a indicação de danos consideráveis em edificações de má qualidade, queda de reboco e tijolos mal assentados, trincas em construções bem feitas e a dificuldade das pessoas a se manterem em pé.

A zona 4 é inteiramente relacionada à aceleração de $15 \% \mathrm{~g}$, que seria a transição entre as intensidades VII e VIII. A intensidade VIII já é bem mais forte nas consequências, com danos em construções normais, inclusive com colapso parcial, queda de monumentos, torres e reservatórios.

É interessante perceber que a literatura atribui a intensidade VII apenas aos sismos de João Câmara/RN (5,1 mR, em 1986); ao de Pacajus/CE (5,2 mR, em 1980), que se constitui no maior sismo já ocorrido na região Nordeste, com consequências similares ao ocorrido em João Câmara); e ao de Codajás/AM (5,5 mb, em 1983). Ao sismo de Itacarambi/MG (4,9 mb, em 2007) é associada a intensidade VI. A nenhum sismo do Brasil foi associada a intensidade VIII, especialmente porque os maiores terremotos ocorreram em regiões relativamente desabitadas. Acredita-se, inclusive, que o mesmo sismo da Serra do Tombador (1955), caso repetido hoje, provocaria consequências muito mais sérias em função do povoamento da área. Um evento de magnitude 5 é geralmente sentido até 200 - $500 \mathrm{~km}$ de distância, e um outro de magnitude 4,5 é percebido até $100 \mathrm{~km}$, ou mais.

\section{CONCLUSÕES}

A atividade sísmica no Brasil é realmente baixa, possivelmente indicando que estas ações podem ser desprezadas para a maioria dos projetos de edificações, em várias partes do território, desde que estas sejam planejadas e executadas de acordo com a boa técnica convencional. Em relação aos prédios de operação especial e uso coletivo, como hospitais, escolas, quartéis de polícia e do corpo de bombeiros, sedes de governo, centrais de comunicação, de segurança e de 
operações em emergência, estações de tratamento de água e esgoto, por exemplo, deveria haver rigor maior, necessitando uma adequada discussão acerca do risco que se admite, e das providências necessárias visando mitigar a vulnerabilidade.

A norma brasileira de projeto de estruturas submetidas a sismo, NBR 15421, precisa ser reavaliada. Primeiro, porque não contempla um conjunto de estruturas importantes, como pontes, viadutos, torres e outras obras, para as quais seria ainda mais importante a avaliação das ações sísmicas. Segundo, para ajustar o mapa das zonas sísmicas e a indicação do perigo sísmico à realidade brasileira com suas peculiaridades. Assumpção et al. (2014, p. 55), por exemplo, fazem a indicação das 7 (sete) principais áreas ativas do país.

Os terremotos são imprevisíveis, mas a boa engenharia não deve ser. O meio técnico deve discutir com rigor científico este tema. É possível, ademais, que o próprio projeto estrutural convencional seja suficiente para suportar com folga as ações sísmicas, mas as incertezas seriam radicalmente diminuídas. Como rotina, existem medidas simples relativas à concepção arquitetônica e estrutural das edificações que poderiam ser incorporadas facilmente e que promoveriam a redução do risco sísmico.

\section{REFERÊNCIAS BIBLIOGRÁFICAS}

1. ASSOCIAÇÃO BRASILEIRA DE NORMAS TÉCNICAS. Projeto de estruturas resistentes a sismos procedimento - NBR 15421. Rio de Janeiro, 2006.

2. ASSUMPÇÃO, M. et al. Intraplate seismicity in Brazil. In: P. Talwani. (Org.). Intraplate earthquakes. 1ed. Cambridge. Cambridge University Press, 2014, v. 1, p. 50-71.

3. DANTAS, R.O.O.; NÓBREGA, S.H.S.; NÓBREGA, P.G.B. Uma discussão prática e didática da norma brasileira NBR 15421 para o projeto de estruturas considerando ações sísmicas. 56으 Congresso Brasileiro do Concreto - IBRACON. Natal, IBRACON, 2014.

4. DANTAS, R.O.O.; NÓBREGA, S.H.S.; NÓBREGA, P.G.B. Conceitos para a concepção de estruturas sismorresistentes. 560 Congresso Brasileiro do Concreto - IBRACON. Natal, IBRACON, 2014.

5. GSHAP - The Global Seismic Hazard Assessment Program. Global Seismic Hazard Map. Disponível em: <http://www.seismo.ethz.ch/GSHAP>. Acesso em: 8 jun 2016.

6. LOPES, A.E.V., NUNES, L.C. Intensidades sísmicas de terremotos: formulação de cenários sísmicos no Brasil. Revista USP, São Paulo, v. 91, p. 90-102, 2011.

7. PAIVA NETO, J.B.; NÓBREGA, P.G.B.; NÓBREGA, S.H.S. Avaliação da resposta sísmica de edifícios de concreto na região nordeste segundo métodos da NBR 15421. 58을 Congresso Brasileiro do Concreto - IBRACON. Belo Horizonte, IBRACON, 2016. /no prelo/

8. STOLOVAS, S.E. Metodologia de avaliação simplificada da vulnerabilidade sísmica de estruturas e sua adaptação ao Brasil. Revista Engenharia, Instituto de Engenharia. São Paulo, v. 592, p. 126-130, 2009.

9. VASCONCELOS, A. Risco sísmico no Brasil e seu impacto sobre grandes obras. Jornal do Instituto de Engenharia, Instituto de Engenharia. São Paulo, v. 58, p. 7, 2010. 